\title{
Variations in the prevalence of point (pre) hypertension in a Nigerian school-going adolescent population living in a semi-urban and an urban area
}

\author{
Chukwunonso ECC Ejike ${ }^{1,3^{*}}$, Chidiebere E Ugwu ${ }^{2,3}$, Lawrence US Ezeanyika ${ }^{2,3}$
}

\begin{abstract}
Background: Hypertension has been shown to start in early life and to track into adulthood. Detecting adolescents with hypertension and prehypertension will aid early intervention and reduce morbidity and mortality from the disorders. This study reports the point-prevalence of the two disorders in a semi-urban and an urban population of school-going adolescents in Nigeria.

Methods: A total of 843 adolescents from two places of domicile were studied. Their blood pressures and anthropometric indices were measured using standard protocol. Point-hypertension and point-prehypertension were defined with respect to each subject's gender, age and height. The prevalence of the disorders was calculated and reported age-wise and nutritional status-wise.

Results: The prevalence of point-prehypertension in the semi-urban area was $22.2 \%$ (20.7\% for girls and $23.1 \%$ for boys) while it was $25.0 \%$ (21.8\% for girls and $29.2 \%$ for boys) in the urban area. The prevalence of pointhypertension was $4.6 \%$ (4.1\% for girls and $4.8 \%$ for boys) in the semi-urban area and $17.5 \%$ (18.0\% for girls and $16.9 \%$ for boys) in the urban area. Point-prehypertension was not detected among the thin subjects of both places of domicile. The prevalence of point-prehypertension was similar in both the urban and semi-urban areas among the subjects who had normal BMI-for-age, and over-weight/obese subjects respectively. From the semi-urban to the urban area, the prevalence of point-hypertension increased approximately 3-folds among thin and normal BMIfor-age subjects, and 10-folds among overweight/obese subjects. Systolic hypertension was more preponderant in both the semi-urban and urban areas.
\end{abstract}

Conclusions: The prevalence of both disorders is considerably high in the studied populations. Urgent pediatric public health action is needed to address the situation.

\section{Background}

High blood pressure causes one in every eight deaths world wide, making it the third leading killer in the world [1]. About one billion adults, the world over, had hypertension in the year 2000, and the number is expected to rise to 1.56 billion in 2025 [2]. Studies have shown that hypertension may begin in adolescence, perhaps even in childhood, and tracks into adulthood [3-5]. Hypertension in adolescents however often goes

\footnotetext{
* Correspondence: nonsoejikeecc@yahoo.com
'Department of Biochemistry, Michael Okpara University of Agriculture,

* Correspondence: nonsoejikeecc@yahoo.com
${ }^{1}$ Department of Biochemistry, Michael Okpara University of Agriculture, Umudike, Nigeria
}

(c) 2010 Ejike et al; licensee BioMed Central Ltd. This is an Open Access article distributed under the terms of the Creative Commons Attribution License (http://creativecommons.org/licenses/by/2.0), which permits unrestricted use, distribution, and reproduction in any medium, provided the original work is properly cited.

undiscovered because adolescents are generally healthy and visit a physician only when they are very ill. For this reason, the measurement of blood pressure even among adolescents has been recommended [6]. High blood pressure is the major risk factor for cardiovascular diseases and detecting it in adolescents may be vital to cardiovascular disease control in adult life [7]. Detecting adolescents with prehypertension would help in identifying those to be targeted for early management. Data from adolescent hypertension studies show prevalence rates ranging from $1.3 \%$ to $21.6 \%$, [8-35] but data on the prevalence of prehypertension in adolescents is rather 
sparse. This study investigated the prevalence of pointprehypertension and point-hypertension in adolescents from two localities in Kogi state, Nigeria. The findings are expected to be useful in pediatric public health policy formulation and action.

\section{Methods}

This study is an analysis of a sub-set of a study of adolescents in Kogi state, Nigeria [36]. The study site and methods were appropriately described in the said study. Data for 843 adolescents (attending public secondary schools) in Lokoja (urban) and Ajaokuta (semi-urban) who were between 13 years and 18 years were included for analysis in the present study. Those aged 10-12 years and 19-20 years, and rural dwellers, in the previous study were excluded because their sample sizes were so small that objective statistical deductions cannot be made from them. Semi-urban area, here, refers to a town where some of the inhabitants are skilled or unskilled artisans, but still engage in farming and the others, say $60 \%$, engage in subsistence farming; while urban area refers to a town with virtually all the trappings of a city - good paved roads, electricity, pipe-borne water and almost all the inhabitants do not engage in subsistence agriculture.

Three separate blood pressure (BP) readings were taken per subject, at two minutes intervals, after an initial 10 minutes rest, in a seated position, using an automated digital monitor (Omron HEM-741 CINT), and appropriate cuff sizes. The device has an error of measurement of $\pm 3 \mathrm{mmHg}$, according to the manufacturers. The average of the last two readings was recorded for both systolic and diastolic blood pressures of each student. Each subject was thereafter asked if he/ she ever had a BP measurement in the past, and the response recorded. The same trained personnel took all blood pressure measurements.

Height was measured (to the nearest $0.5 \mathrm{~cm}$ ) using a non-elastic measuring tape, fastened to a vertical wall, with the student standing on bare feet. Weight was measured (with the student on bare feet and with light clothing) using an electronic weighing balance, to the nearest $0.1 \mathrm{~kg}$. From the heights and weights got, Body Mass Index (BMI) was calculated using the formula BMI $=$ Weight $(\mathrm{kg}) /[\text { Height }(\mathrm{m})]^{2}$. All the equipments were calibrated each morning according to the manufacturer's instructions. All anthropometric variables were measured by the same trained personnel.

Normal blood pressure (NBP) is taken as systolic and diastolic blood pressure that is $<90^{\text {th }}$ percentile for gender, age and height. Prehypertension is taken as systolic and diastolic blood pressure $\geq 90^{\text {th }}$ percentile, but $<95^{\text {th }}$ percentile for gender, age and height or $\geq 120 / 80 \mathrm{mmHg}$ [6]. Hypertension is taken as systolic and diastolic blood pressure $\geq 95^{\text {th }}$ percentile for gender, age and height [6].
Subjects whose blood pressures were $\geq 90^{\text {th }}$ percentile for gender, age and height were taken to have elevated blood pressure (EBP). Thinness and overweight/obesity were defined as BMI-for-age $<5^{\text {th }}$ percentile and $>85^{\text {th }}$ percentile of the first US National Health and Nutrition Examination Survey (NHANES I) 1971-1974 reference data for blacks $[37,38]$ as approved by the World Health Organization (WHO) [39]. Normal BMI-for-age was taken as values $\geq 5^{\text {th }}$ percentile but $\leq 85^{\text {th }}$ percentile of the reference data.

Only subjects who were apparently without any overt signs of ill health and who gave an informed verbal consent after consulting with their parents/guardians were allowed to participate in the study. The study protocol and design were approved by the Ethics committee of the Department of Biochemistry, Kogi state University, Anyigba.

Descriptive statistics was done for SBP and DBP for subjects with NBP and EBP within the ages and data presented in line graphs. Group comparisons were done between the sexes for SBP and DBP in all the ages using the ANOVA test and $\mathrm{p}$ values $<0.05$ were considered significant. To calculate the prevalence of the disorders, we divided the number of such cases by the number of subjects in that category, and multiplied the answer by 100. All data analyses were done using the statistical software SPSS version 11.0 (SPSS Inc. Chicago IL). Data are presented in tables and line graphs.

\section{Results}

The prevalence of point-prehypertension in the semiurban population increased with increasing age from $15.1 \%$ (13 years) to $37.2 \%$ (18 years). For the semi-urban dwelling boys, point-prehypertension prevalence was highest at 17 years, while for their female counterparts, it was highest at 18 years. Irrespective of sex, the prevalence of point-prehypertension in the semi-urban area is 22.2\% (Table 1).

In the urban area, the prevalence of point-prehypertension also increased with increasing age. At 13 years, the figure stood at $5.3 \%$ but increased more than 7 -folds to $37.9 \%$ at 18 years. As much as $33.3 \%$ of the girls aged 18 years in the urban area had point-prehypertension. The prevalence of point-prehypertension in the urban area irrespective of sex is $25.0 \%$ (Table 1 ).

Point-hypertension was most prevalent in subjects aged 14 and 15 years (6.8\% and $6.4 \%$ respectively) in the semi-urban area. In this place of domicile, point-hypertension was absent in those aged 18 years. A total of $4.6 \%$ of the semi-urban dwellers (4.8\% for boys and $4.1 \%$ for girls) had point-hypertension (Table 1).

In the urban area, point-hypertension was absent in adolescents aged 13 years. The prevalence of pointhypertension was highest $(22.4 \%)$ at age 18 years, 
Table 1 Age-wise prevalence of point-prehypertension and point-hypertension in the population

\begin{tabular}{|c|c|c|c|c|c|c|c|c|c|c|c|c|c|c|c|c|c|c|}
\hline \multirow[t]{3}{*}{ AGE (Yrs) } & \multicolumn{9}{|c|}{ SEMI-URBAN AREA } & \multicolumn{9}{|c|}{ URBAN AREA } \\
\hline & \multicolumn{3}{|c|}{ BOYS } & \multicolumn{3}{|c|}{ GIRLS } & \multicolumn{3}{|c|}{ TOGETHER } & \multicolumn{3}{|c|}{ BOYS } & \multicolumn{3}{|c|}{ GIRLS } & \multicolumn{3}{|c|}{ TOGETHER } \\
\hline & $\mathrm{N}$ & $\begin{array}{l}\text { PHT } \\
\text { (\%) }\end{array}$ & $\begin{array}{l}\mathrm{HT} \\
(\%)\end{array}$ & $\mathrm{N}$ & $\begin{array}{l}\text { PHT } \\
\text { (\%) }\end{array}$ & $\begin{array}{l}\text { HT } \\
(\%)\end{array}$ & $\mathrm{N}$ & $\begin{array}{l}\text { PHT } \\
(\%)\end{array}$ & $\begin{array}{l}\text { HT } \\
(\%)\end{array}$ & $\mathrm{N}$ & $\begin{array}{l}\text { PHT } \\
\text { (\%) }\end{array}$ & $\begin{array}{l}\mathrm{HT} \\
(\%)\end{array}$ & $\mathrm{N}$ & $\begin{array}{l}\text { PHT } \\
\text { (\%) }\end{array}$ & $\begin{array}{l}\mathrm{HT} \\
(\%)\end{array}$ & $\mathrm{N}$ & $\begin{array}{l}\text { PHT } \\
(\%)\end{array}$ & $\begin{array}{l}\mathrm{HT} \\
(\%)\end{array}$ \\
\hline 13 & 65 & 16.9 & 1.5 & 41 & 12.2 & 2.4 & 106 & 15.1 & 1.9 & 3 & 0.0 & 0.0 & 16 & 6.3 & 0.0 & 19 & 5.3 & 0.0 \\
\hline 14 & 86 & 17.4 & 8.1 & 46 & 26.1 & 4.3 & 132 & 20.5 & 6.8 & 10 & 10.0 & 40.0 & 33 & 18.2 & 6.1 & 43 & 16.3 & 14.0 \\
\hline 15 & 58 & 20.7 & 6.9 & 36 & 19.4 & 5.6 & 94 & 20.2 & 6.4 & 36 & 13.9 & 13.9 & 48 & 27.1 & 18.8 & 84 & 21.4 & 16.7 \\
\hline 16 & 30 & 30.0 & 3.3 & 28 & 32.1 & 7.1 & 58 & 31.0 & 5.2 & 35 & 34.3 & 17.1 & 58 & 22.4 & 22.4 & 93 & 26.9 & 20.4 \\
\hline 17 & 27 & 40.7 & 3.7 & 23 & 21.7 & 4.3 & 50 & 32.0 & 4.0 & 30 & 36.7 & 6.7 & 33 & 18.2 & 27.3 & 63 & 27.0 & 17.5 \\
\hline 18 & 24 & 37.5 & 0.0 & 19 & 36.8 & 0.0 & 43 & 37.2 & 0.0 & 40 & 40.0 & 22.5 & 18 & 33.3 & 22.2 & 58 & 37.9 & 22.4 \\
\hline Total & 290 & 23.1 & 4.8 & 193 & 20.7 & 4.1 & 483 & 22.2 & 4.6 & 154 & 29.2 & 16.9 & 206 & 21.8 & 18.0 & 360 & 25.0 & 17.5 \\
\hline
\end{tabular}

PHT and HT stand for point-prehypertension and point-hypertension respectively

irrespective of sex, in the urban area. However, it was more prevalent at 14 years for males $(40.0 \%)$ and 17 years for females $(27.3 \%)$. The prevalence of pointhypertension in the urban area is $16.9 \%$ (boys), $18.0 \%$ (girls) and 17.5\% (irrespective of sex) (Table 1).

More than $80 \%$ of the studied population irrespective of place of domicile had normal BMI-for-age values. In the semi-urban and urban areas, $25.3 \%$ and $26.2 \%$ respectively of those with normal BMI-for-age had point-prehypertension, while $4.6 \%$ and $15.0 \%$ of the same group, irrespective of sex had point-hypertension. Urban-dwelling boys who had normal BMI-for-age had a higher prevalence of point-prehypertension than their semi-urban counterparts (31.9\% and $28.4 \%$ respectively). Those of the females were however closer $(21.9 \%$ for urban females and $21.5 \%$ for semi-urban females). The prevalence of point-hypertension was close between urban-dwelling males and females who had normal BMI-for-age (15.2\% and $14.8 \%$ respectively) but not so in the semi-urban population (5.6\% for males and $3.4 \%$ for females) (Table 2).

A total of $15.3 \%$ of the semi-urban population were overweight/obese, as against the $9.2 \%$ recorded in the urban area. Totally, $10.8 \%$ and $18.2 \%$ of those who were overweight/obese in the semi-urban and urban areas respectively had point-prehypertension. Also
$4.1 \%$ and $42.4 \%$ respectively of the same group had point-hypertension. Both point-prehypertension and point-hypertension were more prevalent in the overweight/obese females compared to their male counterparts (Table 2).

Mean systolic blood pressure was highest at 14 years (in boys) who had elevated blood pressures. The differences between the mean systolic blood pressures of the boys and the girls of the same age, who had elevated blood pressures was not significant $(p>0.05)$. Among the normotensive subjects, mean systolic blood pressure was highest at 15 years for boys and 17 years for girls. Normotensive males had a slightly and insignificantly ( $p>0.05$ ) higher mean systolic blood pressures compared to their female counterparts, in all the ages except at 13 years where the females had slightly higher mean systolic blood pressures than the males (Figure 1).

The mean diastolic blood pressures, for both boys and girls of both blood pressure divides, all fell within the normal range. Mean diastolic blood pressure was highest for boys with elevated blood pressure at 14 years and 18 years, but at 14 years and 16 years for girls of the same category. In the subjects with elevated blood pressures, mean diastolic blood pressures was not significantly different $(\mathrm{p}>0.05)$ between both sexes at any given age. For normotensive subjects, mean diastolic blood

Table 2 BMI-wise prevalence of point-prehypertension and point-hypertension in the population

\begin{tabular}{|c|c|c|c|c|c|c|c|c|c|c|c|c|c|c|c|c|c|c|}
\hline \multirow[b]{3}{*}{$\begin{array}{l}\text { Nutritional } \\
\text { status }\end{array}$} & \multicolumn{9}{|c|}{ SEMI-URBAN AREA } & \multicolumn{9}{|c|}{ URBAN AREA } \\
\hline & \multicolumn{3}{|c|}{ BOYS } & \multicolumn{3}{|c|}{ GIRLS } & \multicolumn{3}{|c|}{ TOGETHER } & \multicolumn{3}{|c|}{ BOYS } & \multicolumn{3}{|c|}{ GIRLS } & \multicolumn{3}{|c|}{ TOGETHER } \\
\hline & $N$ & $\begin{array}{l}\text { PHT } \\
(\%)\end{array}$ & $\begin{array}{l}\mathrm{HT} \\
(\%)\end{array}$ & $\mathrm{N}$ & $\begin{array}{l}\text { PHT } \\
(\%)\end{array}$ & $\begin{array}{l}\mathrm{HT} \\
(\%)\end{array}$ & $N$ & $\begin{array}{l}\text { PHT } \\
(\%)\end{array}$ & $\begin{array}{l}\text { HT } \\
(\%)\end{array}$ & $N$ & $\begin{array}{l}\text { PHT } \\
(\%)\end{array}$ & $\begin{array}{l}\mathrm{HT} \\
(\%)\end{array}$ & $\mathrm{N}$ & $\begin{array}{l}\text { PHT } \\
(\%)\end{array}$ & $\begin{array}{l}\text { HT } \\
(\%)\end{array}$ & $\mathbf{N}$ & $\begin{array}{l}\text { PHT } \\
(\%)\end{array}$ & $\begin{array}{l}\text { HT } \\
(\%)\end{array}$ \\
\hline Thin & 13 & 0.0 & 7.7 & 4 & 0.0 & 0.0 & 17 & 0.0 & 5.9 & 5 & 0.0 & 20.0 & 1 & 0.0 & 0.0 & 6 & 0.0 & 16.7 \\
\hline Normal & 215 & 28.4 & 5.6 & 177 & 21.5 & 3.4 & 392 & 25.3 & 4.6 & 138 & 31.9 & 15.2 & 183 & 21.9 & 14.8 & 321 & 26.2 & 15.0 \\
\hline $\begin{array}{l}\text { Overweight/ } \\
\text { obese }\end{array}$ & 62 & 9.7 & 1.6 & 12 & 16.7 & 16.7 & 74 & 10.8 & 4.1 & 11 & 9.1 & 36.4 & 22 & 22.7 & 45.5 & 33 & 18.2 & 42.4 \\
\hline Total & 290 & 23.1 & 4.8 & 193 & 20.7 & 4.1 & 483 & 22.2 & 4.6 & 154 & 29.2 & 16.9 & 206 & 21.8 & 18.0 & 360 & 25.0 & 17.5 \\
\hline
\end{tabular}

PHT and HT stand for point-prehypertension and point-hypertension respectively 

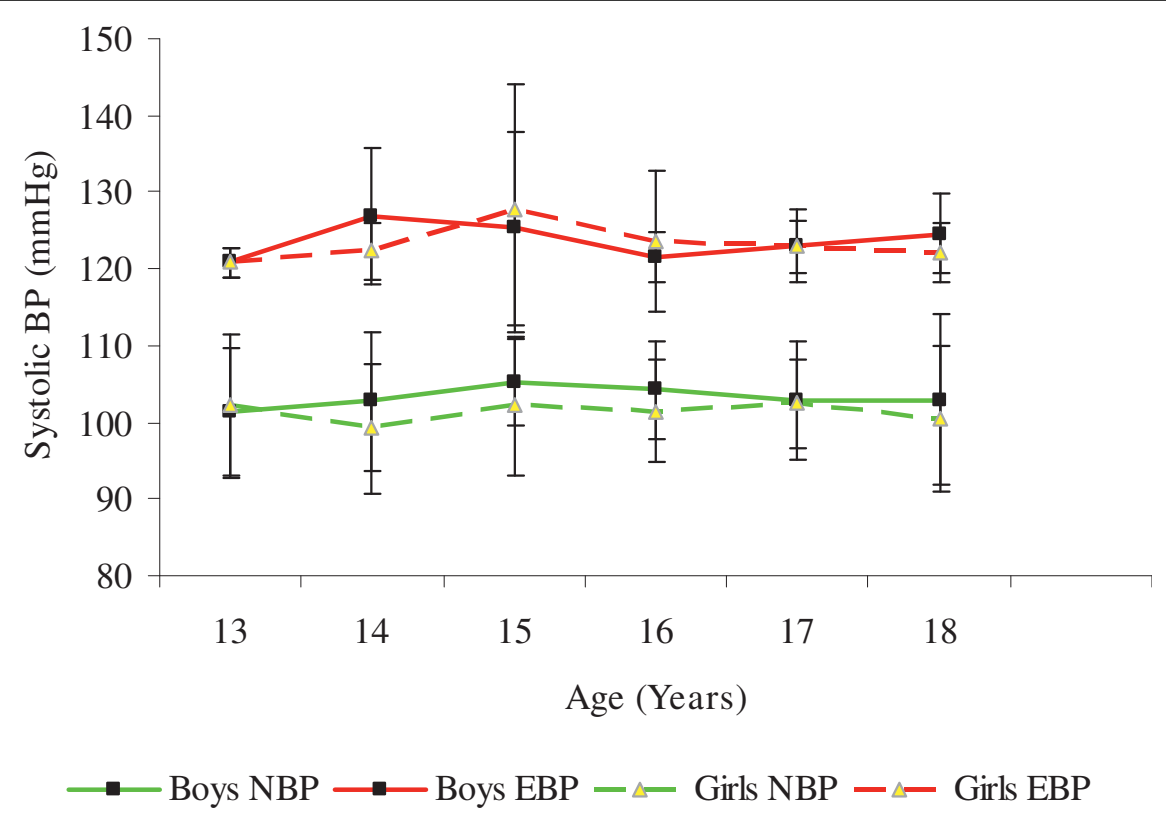

$\mathrm{BP}, \mathrm{NBP}$ and EBP represent blood pressure, normal blood pressure and elevated blood pressure respectively.

Figure 1 Mean systolic blood pressures of subjects with normal and elevated blood pressures (NBP and EBP respectively). Differences between SBP means between the sexes for those with EBP and NBP (within the ages) were not significant $(p>0.05)$.

pressures peaked at 15 years and 17 years for boys and 18 years for girls (Figure 2). The differences between the mean diastolic blood pressures of male and female normotensives were not significant $(p>0.05)$ at any given age.

All the subjects reported being naïve to blood pressure measurement and none of those with elevated blood pressure was therefore aware of the condition.

\section{Discussion}

Prehypertension is considered to be an indication of heightened risk for developing hypertension. Individuals in such category therefore need preventive healthrelated behaviors or therapeutic lifestyle changes [6]. Unfortunately, there is little or no data on adolescents with prehypertension especially in Nigeria. The $22.2 \%$ (23.1\% for boys and $20.7 \%$ for girls) prevalence of pointprehypertension in the semi-urban area in this study; and the $25.0 \%$ (29.2\% for boys and $21.8 \%$ for girls) prevalence for the same disorder in the urban area are quite high. The figures suggest that a large proportion of adolescents that were hitherto considered normotensive are actually at 'high risk' of developing hypertension. The increase in the proportion of adolescents with point-prehypertension from the semi-urban area to the urban area may be supportive of the claim that a shift in socio-economic gradient [that is usually correlated with an upward shift in geographic place of domicile (rural to urban)] often comes with lifestyle changes that predispose to chronic diseases $[36,40]$.

The prevalence of point-hypertension in the study population, irrespective of place of domicile, is $10.1 \%$. This is slightly higher than figures reported earlier in Nigeria $[8,10]$. It also shows a three-fold increase from figures reported three decades ago in Nigeria [9]. However, when separated based on place of domicile, it becomes clear that the increases have taken place mainly in the urban areas, as the prevalence of point-hypertension there was as high as $17.5 \%$ as against $4.8 \%$ in the semi-urban area. The prevalence of point-hypertension in the semi-urban area compares with figures from other (mostly developed) parts of the world [20,24,30,34]. This is worrisome and calls for urgent attention. However, what is more worrisome is that the prevalence of pointhypertension in the urban population is almost a 4-fold increase from the semi-urban group, and is one of the highest in recorded literature. The implications of such high rates on adult morbidity and mortality, and the burden it could place on health systems in Nigeria are palpable. These high rates of these disorders may be due to the rapidly changing lifestyles that come with urbanization - lifestyles that encourage unhealthy diets and habits, and reduced physical exertion, all of which predispose to chronic diseases [36]. 


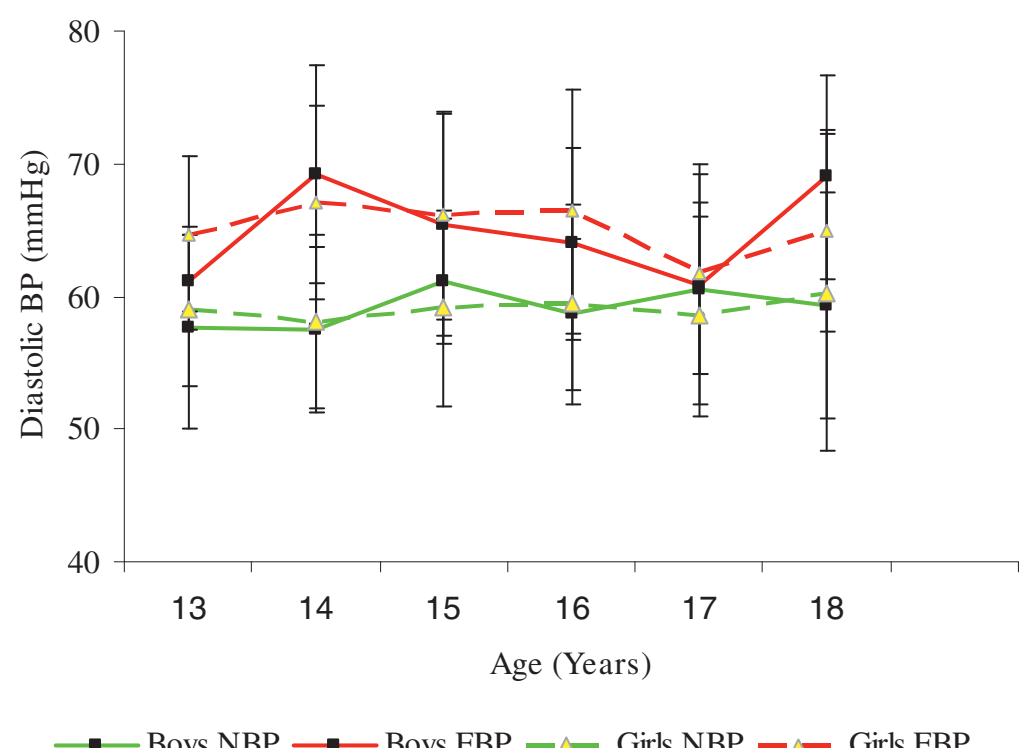

BP, NBP and EBP represent blood pressure, normal blood pressure and elevated blood pressure respectively.

Figure 2 Mean diastolic blood pressures of subjects with normal and elevated blood pressures (NBP and EBP respectively). Differences between DBP means between the sexes for those with EBP and NBP (within the ages) were not significant $(p>0.05)$.

As against point-prehypertension (in the urban area only), there was no significant sex difference in the prevalence of point-hypertension in both semi-urban and urban areas. This agrees with the reports of Chadha et al [16] and Prabhjot et al [7].

The prevalence of point-prehypertension increased almost 3-folds from the normal BMI-for-age group to the overweight/obese group only among the girls in the semi-urban area. The reverse was the case for boys in both places of domicile. The prevalence of point-hypertension increased almost 2-folds and 3-folds from the normal BMI-for-age group to the overweight/obese group among boys and girls, respectively in the urban area. In the semi-urban area, the increase was almost 5folds in the same direction for girls but not boys. Pointprehypertension and point-hypertension increased with increasing BMI-for-age only in the girls of both localities while point-hypertension increased in the same vein only in urban boys. The relationship between blood pressure and BMI has been severally demonstrated in epidemiologic studies $[14,17,28,29,36,41,42]$. Hypertension in overweight/obese and overweight adolescents may arise from increased cardiac output, physical inactivity, excessive sodium intake and alteration in receptors for various presser substances [14].

The increase in mean systolic and diastolic blood pressures with increasing age is one of the most reproducible findings in the blood pressure epidemiologic literature. The differences in mean systolic and diastolic blood pressure values of both normotensive subjects and those with elevated blood pressures did not vary significantly between the sexes. This may be due to physiological and biochemical factors not accounted for in this work. The fact that the mean diastolic blood pressures for both boys and girls, who had elevated blood pressure or were normotensive, all fell within the normal range suggests a preponderance of systolic hypertension in the studied population. This is in agreement with some previous studies [27,43,44]. Mancia et al [45] earlier reported that systolic hypertension in children represents an early stage of essential hypertension that may indicate a hyperdynamic state which may be a pointer to basal sympathetic nervous system hyperactivity.

The fact that none of the subjects with elevated blood pressure was aware of the condition is an important finding. Dindar et al [25] had earlier reported similar findings. In fact, none of the subjects reported having had his/her blood pressure measured at any time, prior to this study. This corroborates the need for routine blood pressure monitoring in children and adolescents as that would help in the early initiation of management and by extension, reduce the burden of morbidity and mortality from hypertension and its sequelae.

Our study may be limited by the fact that what we report is 'point-hypertension' and 'point-prehypertension'. Hypertension can only reliably be established after multiple measurements on at least three different occasions. This deficiency could imply an over-estimation of 
the disorders in our study. We also used an oscillometric device as against the standard auscultation protocol. Oscillometric devices may not always match blood pressure values obtained by auscultation [46] but they have been shown to be valid for use in children and adolescents [42,47]. Our figures may even under-estimate the population with the disorders as automated devices are known to give lower blood pressure values than auscultation [48]. However, when viewed vis-à-vis the measurement of BP on a single visit, as we did, which may over-estimate the problems, our figures may be representative of the true situation in the studied population. We did not also assess factors like pubertal maturation, food choices, genetics, salt intake, etc, all of which may affect blood pressure elevation. Our small sample size especially at age 13 years in the urban area is due to non-cooperation by the students in that age range, while that of semi-urban 18 year-olds is due to the high rate of "school-drop-out syndrome" in the semi-urban area, as adolescents often drop out of school in order to earn a living and support their families, or as a result of marriage and pregnancy (for the girls). This precludes any objective interpretation of the data especially at those ages. Our study is representative of school-going adolescents in both localities. Extrapolating the findings to the general population (especially for other cultures) should be done cautiously.

\section{Conclusion}

The prevalence of point-prehypertension and pointhypertension are considerably high in the studied populations. None of the affected subjects knew of the condition(s). Urgent public health action (like routine examination of BP of children and adolescents at each visit to the physician and before registration into secondary schools, the inclusion of hypertension-preventive health related behaviors in the Health Education curricula of schools and public enlightenment campaigns by government and public spirited individuals and organizations) is solicited, in order to fore-stall or attenuate the implications of adolescent hypertension especially as it tracks into adulthood.

\section{Acknowledgements}

We are very grateful to the Principals, staff and students of the schools that participated in this study.

\section{Author details}

'Department of Biochemistry, Michael Okpara University of Agriculture, Umudike, Nigeria. ${ }^{2}$ Department of Biochemistry, Kogi State University, Anyigba, Nigeria. ${ }^{3}$ Department of Biochemistry, University of Nigeria, Nsukka, Nigeria.

\section{Authors' contributions}

CECCE participated in the study design, analyzed and interpreted the data and wrote the manuscript. CEU conceived the study, participated in its design and coordinated data collection. LUSE participated in study design, and critically vetted the manuscript. All authors read and approved the final version of the manuscript.

\section{Competing interests}

The authors declare that they have no competing interests.

Received: 6 March 2009

Accepted: 9 March 2010 Published: 9 March 2010

References

1. World Health Organization: The World Health Report 2002: Reducing risks, promoting healthy life. Geneva, Switzerland 2002

2. Kaerney PM, Whelton M, Reynolds SK, Munter P, Whelton PK, He J: Global burden of hypertension: an analysis of world wide data. Lancet 2005, 365:217-23.

3. Kotchen JM, McKean HE, Neill M, Kotchen TA: Blood pressure trends associated with changes in height and weight from early adolescence to young adulthood. J Clin Epidemiol 1989, 42:735-41.

4. Young LC, Kuller LH, Rutan G, Bunker C: Longitudinal study of blood pressure changes and determinants from adolescence to middle age. The Dormont high school follow-up study, 1957-1963 to 1989-1990. Am J Epidemiol 1993, 138:973-83.

5. Nelson MJ, Ragland DR, Syme SL: Longitudinal prediction ofadult blood pressure from juvenile blood pressure levels. Am J Epidemiol 1992, 136:633-45.

6. National High Blood Pressure Education Program Working Group on High Blood Pressure in Children and Adolescents: The fourth report on the diagnosis, evaluation and treatment of high blood pressure in children and adolescents. Peadiatrics 2004, 114:555-76.

7. Prabhjot A, Kaur N, Kumar K, Sighu S: Variation in blood pressure among school children in Amristar (Punjab). Anthropologist 2005, 7:201-4.

8. Obika LF, Adedoyin MA, Olowoyeye JO: Pattern of paediatric blood pressure in rural, semi-urban and urban communities in llorin, Nigeria. Afr J Med Sci 1995, 24:371-7.

9. Abdurrahman MB, Ochoga SA: Casual blood pressure in school children in Kaduna, Nigeria. Trop Geogr Med 1978, 30:325-9.

10. Mijinyawa MS, lliyasu Z, Borodo MM: Prevalence of hypertension among teenage students in Kano, Nigeria. Niger J Med 2008, 17:173-8.

11. Adams-Campbell LL, Ukoli F, Young MP, Omene J, Nwankwo M, Haile GT, Kuller Lh: An epidemiological assessment of blood pressure determinants in an adolescent population of Nigerians. J Hypertens 1987, 5:575-80.

12. Ghannem H, Khlifa K, Harrabi I, Ben-Abdelaziz A, Gaha R: Study of cardiovascular disease risk factors among urban school children in Souusse, Tunisia. East Mediterr Health J 2000, 6:1046-54.

13. Ampofo EK: Blood pressure distribution in children at Port Moresby, Papua New Guinea. PNG Med J 1989, 32:101-8.

14. Mohan B, Kumar N, Aslam N, Rangbulla A, Kumbkarni S, Sood NK Wander GS: Prevalence of sustained hypertension and obesity in urban and rural school going children in Ludhiana. Ind Heart J 2004, 56:310-4.

15. Soudarssananne MB, Karthigeyan M, Stephen S, Sahai A: Key predictors of high blood pressure and hypertension among adolescents; a simple prescription for prevention. Ind J Comm Med 2006, 31:164-9.

16. Chadha SL, Tandon R, Shekhawat S, Gopinath N: An epidemiolological study of blood pressure in school children (5-14 years) in Delhi. Ind Heart J 1999, 51:178-82.

17. Gupta AK, Ahmad AJ: Normal blood pressures and the evaluation of sustained blood pressure elevation in childhood. Ind Pediatr 1990, 27:33-42.

18. Mangal N, Bansal RK, Barar V: Blood pressure studies in Jaipur children. Ind Pediatr 1989, 26:531-6.

19. Lavoia D, Sharma M, Diwedi V, Belapurkar KM, Marthur PS: Profile of blood pressure in normal school children. Ind Pediatr 1989, 26:531-6.

20. Klimm HD, Reuter-Kuhn I: Prevalence of hypertension in childhood: a study of 21 family physician practices. Fortschr Med 1994, 112:49-52.

21. Ferrara LA, Marotta T, Mainenti G, Borrelli R, Mancini M, Soro S: Resting blood pressure and cardiovascular response to sympathetic stimulation in adolescents. Int J Cardiol 1992, 36:197-201.

22. Maguire $H$, Shelley E: Blood pressure levels among primary school children. Ir Med J 1990, 8:90-4. 
23. Grunberg $H$, Thefloff $M$ : The cardiovascular risk factor profile of Estonian school children. Acta Paediatr 1998, 87:37-42.

24. Cassimos C, Varlamis G, Karamperis S, Katsouyannopoulos V: Blood pressure in children and adolescents. Acta Paediatr Scand 1977, 66:439-43.

25. Dindar I, Saltik A: Hypertension screening among primary school children aged 7-11 in Edirne, Turkey. Proceedings of the 4th National Congress of Public health Didim, Izmir 9 Eylol University Medical School, Izmir Chamber of Medicine 1994, 436-40.

26. Irgil E, Erkenci Y, Aytekin N, Aytekin H: Prevalence of hypertension among school children aged 13-18 years in Gemlik, Turkey. Eur J Pub Health 1998, 8:176-8.

27. Subhi MD: Blood pressure profiles and hypertension in Iraqi primary school children. Saudi Med J 2006, 27:482-6.

28. Jaddou HY, Bateiha AM, Khawaldeh AM, Goussous YM, Ajlouni KM: Blood pressure profile in schoolchildren and adolescents in Jordan. Ann Saudi Med 2001, 21:123-6.

29. Saleh EA, Manfouz AA, Tayel KY, Naguib MK, Bin-al-Shaikh NM: Hypertension and its determinants among primary school children in Kuwait: an epidemiological study. East Mediterr Health J 2000, 6:333-7.

30. Sianiko AR, Gomez-Marin O, Prineas RJ: Prevalence of 'significant' hypertension in junior high school-aged children; the children and adolescent blood pressure program. J Pediatr 1989, 114:664-9.

31. O'Quin M, Sharma BB, Miller KA, Tomsovic JP: Adolescent blood pressure survey: Tulsa, Oklahoma, 1987-1989. S Med J 1992, 85:487-90.

32. King CA, Meadows BB, Engelke MK, Swanson M: Prevalence of elevated body mass index and blood pressure in a rural school-aged population: implications for school nurses. J Sch Health 2006, 76:145-9.

33. Simonatto DM, Dias MD, Machado RL, Abensur H, Cruz J: Arterial hypertension in students of the Great Sao Paulo area. Rev Assoc Med Braz 1991, 37:109-14

34. Lodolo AD, Novoa P, Sakuyama E, Lodolo MM, Palma JA, Martinez JR: Arterial hypertension in children and adolescents. Rev Fac Cien Med Univ Nac Cordoba 1989, 47:19-22.

35. Moura AA, Silva MA, Ferraz MR, Rivera IR: Prevalence of high blood pressure in children and adolescents from the city of Maceio, Brazil. J Pediatr (Rio J) 2004, 80:35-40.

36. Ejike CECC, Ugwu CE, Ezeanyika LUS, Olayemi AT: Blood pressure patterns in relation to geographic area of residence: a cross sectional study of adolescents in Kogi state Nigeria. BMC Public Health 2008, 8:411.

37. Must A, Dallal GE, Dietz WH: Reference data for obesity: $85^{\text {th }}$ and $95^{\text {th }}$ percentiles of body mass index $\left(\mathrm{wt} / \mathrm{ht}^{2}\right)$ and triceps skinfold thickness. Am J Clin Nutr 1991, 53:839-46.

38. Must A, Dallal GE, Dietz WH: Reference data for obesity: $85^{\text {th }}$ and $95^{\text {th }}$ percentiles of body mass index $\left(\mathrm{wt} / \mathrm{ht}^{2}\right)$ - a correction. Am J Clin Nutr $1991,54: 773$.

39. World Health Organization: Physical status: The use and interpretation of anthropometry. WHO Techl Rep Ser No 854 WHO Geneva 1995.

40. Akinkugbe FM, Akinwolere AO, Kayode CM: Blood pressure in Nigerian adolescents. West Afr J Med 1999, 18:196-202.

41. Oli K, Tekle-Haimanot R, Forsgren L, Ekstedt J: Blood pressure patterns and its correlates in school children of an Ethiopian community. J Trop Peadiatr 1994, 40:100-3.

42. Agyemang C, Redekop WK, Owusu-Dabo E, Bruijnzeels MA: Blood pressure patterns in rural, semi-urban and urban children in Ashanti region of Ghana, West Africa. BMC Public Health 2005, 5:114.

43. Sorof JM: Prevalence and consequences of systolic hypertension in children. Am J Hypertens 2002, 15:57S-60S

44. Rosner B, Prineas R, Daniels SR, Loggie J: Blood pressure differences between blacks and whites in relation to body size among US children and adolescents. Am J Epidemiol 2000, 151:1007-19.

45. Mancia G, Di Rienzo M, Paratia G, Grassi G: Sympathetic activity, blood pressure variability and end organ damage. J Hum Hypertens 1997, 11:3S-8S.

46. Park MK, Menard SW, Yuan C: Comparison of ausculatory and oscillometric blood pressures. Arch Pediatr Adolesc Med 2001, 155:50-53.

47. El Assad MA, Topouchain JA, Asmar RG: Evaluation of two devices for selfmeasurement of blood pressure according to the international protocol: the Omron M5-1 and the Omron 7051T. Blood Press Monit 2003, 8:127-33.

48. Lithell $H$, Berglund $L$ : Validation of an oscillometric blood pressure monitoring device: a sub study of the HOT (Hypertension Optimal Treatment) study. Blood Press 1998, 7:149-52.

\section{Pre-publication history}

The pre-publication history for this paper can be accessed here:http://www biomedcentral.com/1471-2431/10/13/prepub

doi:10.1186/1471-2431-10-13

Cite this article as: Ejike et al:: Variations in the prevalence of point (pre)hypertension in a Nigerian school-going adolescent population living in a semi-urban and an urban area. BMC Pediatrics 2010 10:13.

\section{Submit your next manuscript to BioMed Central and take full advantage of:}

- Convenient online submission

- Thorough peer review

- No space constraints or color figure charges

- Immediate publication on acceptance

- Inclusion in PubMed, CAS, Scopus and Google Scholar

- Research which is freely available for redistribution 